\title{
A Poisson and negative binomial regression model of sea turtle interactions in Hawaii's longline fishery
}

\author{
Naresh C. Pradhan, PingSun Leung* \\ Department of Molecular Biosciences and Bioengineering, University of Hawaii at Manoa, \\ 1955 East-West Road Room 218, Honolulu, HI 96822, USA
}

Received 10 February 2005; received in revised form 28 November 2005; accepted 15 December 2005

\begin{abstract}
Sea turtle interactions with the longline fishery in Hawaii have become a serious concern in recent years. Various measures, including a swordfish harvest ban, have been adopted to protect sea turtles. This study explores the factors and degree of sea turtle interactions with Hawaii's pelagic longline fishery, i.e. the production of undesirable outputs in the pursuit of an economic activity, in an analytical framework of rare events using the count data models for the period 1994-2003. The analysis was based on the type of trip, such as those targeting tuna or swordfish. The fishing technologies associated with the choice of trip or target species, season, and turtle population explained turtle interactions with the longline fishery. The impact of a fishing vessel's previous history of turtle interactions had a negligible impact on subsequent interactions. In the absence of new longline fishing technologies to dramatically avert sea turtle interactions, there are about $6 \%$ and $55 \%$ chance that at least one turtle per trip may be encountered in tuna- and swordfish-targeted fishing trips, respectively. This study confirms that more turtle interactions are associated with the swordfish-targeted trips. Several of the factors that contributed substantially to turtle interactions can be feasibly regulated. Furthermore, the conservation and management of sea turtles require increased policy dialogues and cooperation among the coastal nations vis-à-vis the adaptation to "turtle-friendly" fishing technologies.
\end{abstract}

(C) 2006 Elsevier B.V. All rights reserved.

Keywords: Sea turtle interactions; Poisson and negative binomial regression; Pelagic longline fishery; Hawaii

\section{Introduction}

The increased concerns for environmental impacts of fishing activities continue to pose a serious challenge to fishery managers when devising fishery management policies that are economically efficient, environmentally sound, and acceptable to resource users with different interests. Fishery managers are considering more pragmatic regulatory measures to resolve these issues primarily on the ecological front. Addressing these issues is particularly important in the context of the recently preferred ecosystem-based fishery management.

A symbol of longevity, fertility, strength, and protection from harm, sea turtles are revered in cultures and customs around the globe. Coastal populations have exploited sea tur-

\footnotetext{
* Corresponding author. Tel.: +1 808956 8562; fax: +1 8089569269 .

E-mail address: psleung@ hawaii.edu (P. Leung).
}

tles for their meat, eggs, shell, leather, and oil for centuries. Little is known about the principal economic and cultural factors driving egg and turtle harvests in the Pacific region. The latter half of the 20th century has been marked by a catastrophic decline in the sea turtle population throughout the region. Having endured for millions of years, sea turtles are now categorized as critically endangered by the 2000 IUCN (The International Union for the Conservation of Nature and Natural Resources) RedList of threatened species (WPRFMC, 2002).

Recently, the longline fishery, a major component of Hawaii's commercial fishery, has been faced with the challenge of protecting endangered or threatened marine turtle species. There has been a growing concern about increased turtle interactions with the longline fishery. Accounting for their interactions with fishery activities has received much attention in fishery management decisions recently. An increased incidence of sea turtle interactions was noticed 
after an influx of a large number of technologically advanced longline fishing vessels to the state from the continental USA during the late 1980s.

Several species of sea turtles are found near the Northwestern Hawaiian Islands. The most common turtle species so far observed to interact with the longline fishery are loggerhead (Caretta caretta), leatherback (Dermochelys coriacea), olive ridely (Lepidochelys olivacea), and green turtles (Chelonia mydas) (Kleiber, 1998). Other species, such as hawksbill (Eretmochelys imbricate) and some other unidentified hardshell turtles, also interact with the longline fishery. These species migrate vast distances across ocean basins, living successively through various life stages in the high seas and coastal habitats of numerous Pacific nations (WPRFMC, 2002). On their route in search of food they are often snagged on baited hooks and entangled in lines and other fishing gear.

All sea turtles are protected under the Endangered Species Act (ESA) and State of Hawaii regulations. Because of turtle interactions with the longline fishery, policies designed to protect these species may halt the whole fishing operation. Several conservation groups have launched a campaign to abolish longline fishing in an effort to prevent turtle fatalities. A recent lawsuit charging that swordfish-targeted longline fishing is a threat to the survival of turtle populations led to an injunction barring longline fishing targeting swordfish (Xiphias gladius) in certain waters off the Hawaiian Islands. Beginning in the summer of 2000, some tough policies governing Hawaii's longline fishery have been put into effect, including a total ban on swordfish-targeted longline fishery. These regulations have forced some of the vessels primarily targeting swordfish either to leave Hawaii or to switch to tuna fishing. A large number of longline vessels have indeed left Hawaii's waters seeking opportunities elsewhere. However, in early 2004, the restriction on swordfish longlining was conditionally relaxed.

Protected-species interactions with longline fishing can be characterized as rare events analogous to industrial injuries, transport accidents, product innovations, etc. The law of rare events states that the total number of events will follow, approximately, the Poisson distribution if an event may occur in any of a large number of trials, but the probability of occurrence in any given trial is small (Cameron and Trivedi, 1998). The count of such observed interactions is a non-negative integer. A statistical model of counts would be, thus, relevant to analyze the factors and degree of protected-species interactions, such as sea turtles interactions with longline fishing activities. The Poisson distribution is often a reasonable description for events that occur both "randomly and independently" in time, and it is also attractive because it is consistent with the integer nature of the data on turtle interactions. Even though there are situations in which the linear regression model provides reasonable results, it is much safer to use models specifically designed for count outcomes (Long and Freese, 2001).

There are few studies on rare events in the economic literature. Hausman et al. (1984) examined the effect of research and development expenditures on the number of patents received by U.S. firms. Jensen (1987) analyzed the relationships between research expenditures and drug discoveries. Cincera (1997) examined the determinants of patent application. Michener and Tighe (1992) analyzed highway fatalities in the U.S. Sarker and Surry (1998) studied recreational moose hunting in Ontario. Grogger (1990) studied the deterrent effects of capital punishment on daily homicides. McConnell et al. (1995) and O'Neill and Faddy (2003) have used the count data model in their analyses of recreational fisheries in the U.S.

Although endangered turtle interactions with a fishery can be analyzed with models for event count data, they are not found in the literature. The quest for such models in sea turtle interaction analysis has been in situ for quite some time. Hoey (1996) suggests that although distributional characteristics of turtles undoubtedly differ by season, region, and fishery, their distributions will, however, be skewed with a predominance of zero observations. In addition, the positive observations are clustered and contiguous in time and space. The use of mean and median observed catch rates may lead to overestimates of total interactions. Alternative distributional assumptions (Poisson, negative binomial, delta lognormal) or additive models that independently model zero frequencies and positive observations were, therefore, suggested.

There have also been recent attempts to estimate the takes and kills of different sea turtles in Hawaii's longline fishery using non-parametric regression procedures, such as generalized additive model and regression tree analysis (Kleiber, 1998; Skillman and Kleiber, 1998; McCracken, 2000). The magnitude of turtle takes and kills were estimated, but the explanatory variables in these models varied by turtle species. The variables considered were three categories of months fished, latitude as a polynomial, and two categories of temperature for loggerhead; temperature in two categories for olive ridley; latitude in four categories for leatherback; no explanatory variables for green turtles (McCracken, 2000). The data in these studies, however, suffer from severe truncation, e.g. areas where a turtle species were not recorded were excluded from the analysis. This may result in some bias or overestimation in turtle takes and kills rates and possibly a violation of the underlying Poisson assumption used in these studies.

The basic relationship under examination in this article is between the surrounding attributes with the incidence of sea turtle interactions in the longline fishery. Possible factors responsible for the interactions, including vessel-specific characteristics and fishing technologies, spatial, temporal, and physical environment, etc., were investigated. To the best of our knowledge, there are no analytical studies in the literature on sea turtle interactions with a fishery employing the count data models. Furthermore, the present analysis would have added significant information during the deliberations over the recent swordfish ban in that it explains possible factors affecting sea turtle interactions with the longline fishery. 
The next section describes the longline fishery in Hawaii and the issues related to sea turtle interactions with this fishery, followed by an exposition of the empirical models and a description of the data used in the analysis. It is then followed by a presentation of the results and discussion with policy implications.

\section{The longline fishery and sea turtle interactions issues in Hawaii}

\subsection{The longline fishery}

Hawaii-based longline fishery is a year-round, limitedentry, high-seas fishery targeting various billfishes and tunas in the Central Pacific Ocean. Most fishing activity takes place in the region bounded by $0^{\circ}-45^{\circ} \mathrm{N}$ latitude and $180^{\circ}-140^{\circ} \mathrm{W}$ longitude. Vessels targeting swordfish tend to fish to the north of Hawaii along the oceanic frontal or convergence zone of warm tropical water and cooler water from the northern Pacific, while vessels fishing for tuna are predominantly found in the warmer waters to the south of Hawaii (Pooley, 1993). The longline technology was introduced to Hawaii by the Japanese in 1917. Pelagic species dominate the fishery. Fishing depth and timing affects the efficiency with which different fish species are captured-shallower depths (30-90 m) to target swordfish during nights, but deeper ones for tuna during days (Boggs and Ito, 1993). Bigeye tuna (Thunnus obesus) are targeted by deploying 12-25 hooks between floats with enough sag to reach depths of about $400 \mathrm{~m}$, but only three to six hooks are deployed when targeting swordfish. Night-time fishing employs luminescent lightsticks to attract swordfish and their prey to the baited hooks. Longlines deployed for swordfish are conventionally baited with large squid (Illex spp.), but tuna-targeted longlines are usually set during the day and use saury (Cololabis saira) as bait (Dalzell, 2000). By the 1930s, the longline fishery was second only to pole-and-line fishery in landed volume of fish and accounted for most of the yellowfin tuna (Thunnus albacares), bigeye tuna, and albacore (Thunnus alalunga) landed in Hawaii. The fishery peaked in the mid 1950s, and then declined steadily until the late 1980s due to lack of investment in boats and gear. The revitalization of the fishery was due to the development of local and export markets for fresh tuna to the continental USA and Japan, and the discovery of swordfish stocks around Hawaii. Bigeye tuna has been a major target species of the longline fishery since the 1950s, while swordfish was only a minor species until the 1990s (Dollar, 1992; Curran et al., 1996).

Participation in Hawaii longline fishery almost quadrupled from 37 vessels in 1987 to as many as 141 vessels in 1991. This number then leveled off to about 120 vessels between 1992 and 1994, declined slightly to 103 vessels in 1996, and then increased to 125 vessels in 2000 (Ito and Machado, 2001). The older longline vessels measure about 43-70 feet and are capable of taking 2-week trips, while the more modern vessels average 70-100 feet and can travel for 2-3 months (WPRFMC, 1995). The revitalized fleet adopted modern longline gear and a multitude of efficient technologies, such as acoustic doppler, current profilers, chromoscope fish finders, satellite navigation systems, and color video echo sounders (Dollar, 1992; Dalzell, 2000). The longline fishery has also grown to be the largest and most prominent commercial fishery in Hawaii in a short span of time. The commercial pelagic catch totaled about 36 million pounds (16,363 metric tons) with ex-vessel revenue of $\$ 59$ million in 1999 (WPRFMC, 2001). The longline fishery contributed 28.3 million pounds (12,863 metric tons) with ex-vessel revenue of $\$ 47.4$ million in 1999; however, the longline landings and sales declined to 17.2 million pounds (7818 metric tons) and \$37.5 million, respectively, in 2002 after the swordfish harvest ban (WPRFMC, 2004a). Currently, Hawaii's longline fishery represents about $2.7 \%$ of the longline hooks deployed in the entire Pacific. The fishery is considered to be well managed without any serious stock problems (Dalzell, 2000). Until recently, swordfish harvest was banned due to the concern over sea turtle interactions with the shallow-hooked longline used in swordfish fishing, and only deep-hooked longline tuna fishing was permitted.

\subsection{Sea turtle interactions issue}

Several species of sea turtles are found near the Northwestern Hawaiian Islands. Early on in the re-expansion of Hawaii's longline fishery, it became apparent that the vessels fishing close to the Northwestern Hawaiian Islands would on occasion catch animals protected under the ESA, namely the Hawaiian monk seal and the green sea turtle. The relocation of the longline fishery offshore solved the problem of interactions between monk seals, green turtles, and small boat fishermen. However, the longline vessels continued to interact with other marine turtles (Dalzell, 2000). This issue received much attention from policymakers, fishers, and other stakeholders after the recent rapid expansion of the longline fleet in Hawaii. Higher interactions were reportedly with fishing activities targeting swordfish.

A turtle take is defined as an interaction between a turtle and a fishing vessel or gear and usually implies that the turtle became entangled in the line or was caught on a hook (McCracken, 2000). There is poor understanding about the basic sea turtle population, their distribution, habitat, migratory behavior, and magnitude of threats. Nest counts and turtle census are difficult to quantify, total number of breeding adults are still unknown for many breeding beaches, and the age class structure, or composition, of the population is poorly understood. While one can theorize a trend, there are still many unknowns (Cousins, 2002). The National Marine Fisheries Service (NMFS) conducted a review of the fishery which resulted in the issuance of the Biological Opinion 
Table 1

Estimates of turtle takes and kills in Hawaii's longline fishery

\begin{tabular}{|c|c|c|c|c|c|c|c|c|c|c|}
\hline Turtles species & & 1994 & 1995 & 1996 & 1997 & 1998 & 1999 & 2000 & 2001 & 2002 \\
\hline \multirow[t]{2}{*}{ Loggerhead } & Takes & 501 & 412 & 445 & 371 & 407 & 369 & 246 & 18 & 19 \\
\hline & Kills & 88 & 72 & 78 & 65 & 71 & 64 & 106 & 8 & 8 \\
\hline \multirow[t]{2}{*}{ Olive ridley } & Takes & 107 & 143 & 153 & 154 & 157 & 164 & 113 & 36 & 31 \\
\hline & Kills & 36 & 47 & 51 & 51 & 52 & 55 & 65 & 27 & 29 \\
\hline \multirow[t]{2}{*}{ Leatherback } & Takes & 109 & 99 & 106 & 88 & 139 & 132 & 132 & 10 & 6 \\
\hline & Kills & 9 & 8 & 9 & 7 & 12 & 11 & 45 & 3 & 2 \\
\hline \multirow[t]{2}{*}{ Greenback } & Takes & 37 & 38 & 40 & 38 & 42 & 45 & 65 & 11 & 3 \\
\hline & Kills & 5 & 5 & 5 & 5 & 5 & 6 & 35 & 8 & 3 \\
\hline \multirow[t]{2}{*}{ Total } & Takes & 754 & 692 & 744 & 651 & 745 & 710 & 556 & 75 & 59 \\
\hline & Kills & 138 & 132 & 143 & 128 & 140 & 136 & 251 & 46 & 42 \\
\hline
\end{tabular}

Source: WPRFMC (2004b).

and Incidental Take Statement (Opinion) in 15 May 1991. ${ }^{1}$ Based on hearsay information about the takes and opinions on the status of turtle stocks, an allowable take of up to 25 turtles/year was set. Beginning in November 1990, NMFS had also set up to collect detailed information about longline fishing activities from each fisher at the end of the fishing trip. In June 1992, NMFS found that the incidental takes of turtles reported in the 1991 logbooks exceeded the level set in the Opinion. Therefore, based on the recent assessments, NMFS conducted a second investigation to review the reported takes and the status of the turtle stocks. In a 10 June 1993 Opinion, NMFS: (1) determined that Hawaiibased longline fishery did adversely impact the turtle species which were taken in the fishery, but was not likely to jeopardize their continued existence; (2) required the establishment of an observer program and an annual review of turtle take using observer data; (3) revised the allowable take to 752 and mortality to 299 with no more than 150 leatherback turtles mortalities or serious injuries (Skillman and Kleiber, 1998). A federally mandated observer program was put into effect in February 1994 to closely monitor Hawaii-based longline fishing activities. The number of turtle takes by species, their conditions and circumstances, other species of concern, etc. are recorded by the observer for each longline set. Table 1 presents an estimate of the magnitude of turtle interaction with Hawaii's longline fishery from 1994 to $2002 .^{2}$ The estimates of turtle interactions in the entire longline fishery were

\footnotetext{
${ }^{1}$ Under the Biological Opinion, the fishery agency must determine the level of interactions and mortalities and compare these with population dynamics of the affected populations. The opinion can then set limits on the volume of interactions and fatalities, which, if exceeded, require a fresh Biological Opinion (Dalzell, 2000).

2 Data collected by the Secretariat of the Pacific Community suggested relatively low interaction rates in Hawaii's fisheries relative to other fisheries. High-end estimates of about 0.1000 turtles/1000 hooks for Asian fleets (Japanese, Taiwanese, Korean, and other Pacific nations) would indicate interactions of about 12,000-20,000 turtles/year (WPRFMC, 2002). The turtle catch per 1000 hooks in Atlantic longline fishery during 1998-2000 were $0.3270,0.3370-0.7020$, and $0.1600-0.3240$ for loggerhead, leatherback, and olive ridely, respectively (Hsia, 2002). However, the turtle CPUE in Hawaii's longline fishery during 1994-2002 has remained at about 0.0071 turtles/1000 hooks in tuna-targeted longline trips, and 0.1302 in
}

extrapolated from observers' records that comprised approximately $4 \%$ of the fishing trips. The detailed account of turtle interactions by season and trip types and the number of turtle incidences reported by fishers in the logbook records are presented in Table 2.

In February 1999, in an attempt to conserve sea turtles, Earthjustice, representing the Center for Marine Conservation and Turtle Island Restoration Network, filed a lawsuit against NMFS accusing them of negligence in their duty to protect endangered sea turtles. The plaintiffs were concerned about all sea turtles, but focused on the leatherback turtle, as its population in the Pacific had declined considerably over the past two decades. During the hearing in November 1999, the federal court judge found in favor of the defendants (NMFS) with respect to their Biological Opinion on the sea turtles and their interactions with Hawaii-based longline fishery. This meant that while interactions and some fatalities occurred, the judge agreed with the defendants that this had little influence on turtle population. However, the judge agreed with the plaintiffs that NMFS was delinquent under another government statute, the National Environmental Policy Act (NEPA), under which federal policies, laws, and regulations must be assessed with respect to their impact on the environment (Dalzell, 2000).

Based on the data provided by NMFS the majority of turtle interactions, particularly with loggerheads and leatherbacks, occurring to the north of Hawaii were possibly associated with the oceanic convergence zone. Consequently, the judge closed off ocean north of $28^{\circ} \mathrm{N}$ latitude and between $150^{\circ}$ and $168^{\circ} \mathrm{W}$ longitudes; ordered all vessels to carry clippers and dip nets to untangle any hooked turtles; requested NMFS to conduct an analysis of the best combination of time-area closures; for the parties in the case to review the results and make their own recommendations. On 23 June 2000, the judge announced his order for the fishery; it included a closure of all waters between $30^{\circ}$ and $44^{\circ} \mathrm{N}$ latitudes and $137^{\circ} \mathrm{W}-173^{\circ} \mathrm{E}$ longitudes. With fishing between $6^{\circ}$ and $30^{\circ} \mathrm{N}$

swordfish-targeted longline trips. Over $90 \%$ of the turtle interactions in Hawaii are associated with swordfish-targeted longline fishing. 
Table 2

Turtle interactions by season and trip type as reported in the observer and logbook datasets, Hawaii longline fishery

\begin{tabular}{|c|c|c|c|c|c|c|c|c|c|c|c|}
\hline \multirow[t]{3}{*}{ Year } & \multirow[t]{3}{*}{ Season } & \multicolumn{9}{|c|}{ Observer dataset } & \multirow{3}{*}{$\begin{array}{l}\begin{array}{l}\text { Logbook } \\
\text { dataset }\end{array} \\
\begin{array}{l}\text { No. of } \\
\text { turtles }\end{array}\end{array}$} \\
\hline & & \multicolumn{3}{|c|}{ Tuna-targeted trips } & \multicolumn{3}{|c|}{ Swordfish-targeted trips } & \multicolumn{3}{|c|}{ All trips } & \\
\hline & & $\begin{array}{l}\text { No. of } \\
\text { trips }\end{array}$ & $\begin{array}{l}\text { No. of sets with } \\
\text { turtle encounters }\end{array}$ & $\begin{array}{l}\text { No. of } \\
\text { turtles }\end{array}$ & $\begin{array}{l}\text { No. of } \\
\text { trips }\end{array}$ & $\begin{array}{l}\text { No. of sets with } \\
\text { turtle encounters }\end{array}$ & $\begin{array}{l}\text { No. of } \\
\text { turtles }\end{array}$ & $\begin{array}{l}\text { No. of } \\
\text { trips }\end{array}$ & $\begin{array}{l}\text { No. of sets with } \\
\text { turtle encounters }\end{array}$ & $\begin{array}{l}\text { No. of } \\
\text { turtles }\end{array}$ & \\
\hline \multirow[t]{5}{*}{1994} & Spring & 8 & 0 & 0 & 14 & 5 & 11 & 22 & 5 & 11 & 31 \\
\hline & Summer & 1 & 0 & 0 & 9 & 1 & 1 & 10 & 1 & 1 & 8 \\
\hline & Fall & 5 & 0 & 0 & 6 & 4 & 7 & 11 & 4 & 7 & 11 \\
\hline & Winter & 4 & 0 & 0 & 2 & 1 & 9 & 6 & 1 & 9 & 15 \\
\hline & Total & 18 & 0 & 0 & 31 & 11 & 28 & 49 & 11 & 28 & 65 \\
\hline \multirow[t]{5}{*}{1995} & Spring & 5 & 0 & 0 & 7 & 10 & 5 & 12 & 10 & 5 & 29 \\
\hline & Summer & 3 & 0 & 0 & 8 & 2 & 1 & 11 & 2 & 1 & 11 \\
\hline & Fall & 9 & 2 & 2 & 3 & 0 & 0 & 12 & 2 & 2 & 4 \\
\hline & Winter & 14 & 2 & 2 & 1 & 1 & 1 & 15 & 3 & 3 & 19 \\
\hline & Total & 31 & 4 & 4 & 19 & 13 & 7 & 50 & 17 & 11 & 63 \\
\hline \multirow[t]{5}{*}{1996} & Spring & 7 & 0 & 0 & 9 & 4 & 8 & 16 & 4 & 8 & 24 \\
\hline & Summer & 7 & 0 & 0 & 7 & 5 & 12 & 14 & 5 & 12 & 18 \\
\hline & Fall & 7 & 0 & 0 & 4 & 3 & 6 & 11 & 3 & 6 & 3 \\
\hline & Winter & 8 & 0 & 0 & 3 & 2 & 11 & 11 & 2 & 11 & 42 \\
\hline & Total & 29 & 0 & 0 & 23 & 14 & 37 & 52 & 14 & 37 & 87 \\
\hline \multirow[t]{5}{*}{1997} & Spring & 5 & 0 & 0 & 8 & 6 & 9 & 13 & 6 & 9 & 30 \\
\hline & Summer & 3 & 0 & 0 & 1 & 1 & 1 & 4 & 1 & 1 & 9 \\
\hline & Fall & 7 & 2 & 2 & 4 & 1 & 2 & 11 & 3 & 4 & 2 \\
\hline & Winter & 7 & 0 & 0 & 9 & 7 & 22 & 16 & 7 & 22 & 5 \\
\hline & Total & 22 & 2 & 2 & 22 & 15 & 34 & 44 & 17 & 36 & 46 \\
\hline \multirow[t]{5}{*}{1998} & Spring & 4 & 2 & 2 & 2 & 2 & 4 & 6 & 4 & 6 & 54 \\
\hline & Summer & 5 & 0 & 0 & 5 & 2 & 2 & 10 & 2 & 2 & 8 \\
\hline & Fall & 12 & 1 & 11 & 4 & 2 & 7 & 16 & 3 & 18 & 15 \\
\hline & Winter & 6 & 1 & 1 & 8 & 7 & 26 & 14 & 8 & 27 & 21 \\
\hline & Total & 27 & 4 & 14 & 19 & 13 & 39 & 46 & 17 & 53 & 98 \\
\hline \multirow[t]{5}{*}{1999} & Spring & 10 & 2 & 2 & 2 & 2 & 4 & 12 & 4 & 6 & 21 \\
\hline & Summer & 2 & 0 & 0 & 3 & 1 & 1 & 5 & 1 & 1 & 11 \\
\hline & Fall & 2 & 0 & 0 & 1 & 1 & 3 & 3 & 1 & 3 & 29 \\
\hline & Winter & 10 & 2 & 2 & 5 & 5 & 14 & 15 & 7 & 16 & 32 \\
\hline & Total & 24 & 4 & 4 & 11 & 9 & 22 & 35 & 13 & 26 & 93 \\
\hline \multirow[t]{5}{*}{2000} & Spring & 6 & 0 & 0 & 7 & 6 & 12 & 13 & 6 & 12 & 21 \\
\hline & Summer & 6 & 1 & 2 & 3 & 1 & 1 & 9 & 2 & 3 & 12 \\
\hline & Fall & 28 & 3 & 4 & 2 & 1 & 1 & 30 & 4 & 5 & 2 \\
\hline & Winter & 55 & 4 & 6 & 9 & 6 & 12 & 64 & 10 & 18 & 14 \\
\hline & Total & 95 & 8 & 12 & 21 & 14 & 26 & 116 & 22 & 38 & 49 \\
\hline \multirow[t]{5}{*}{2001} & Spring & 49 & 2 & 2 & 2 & 1 & 1 & 51 & 3 & 3 & 12 \\
\hline & Summer & 44 & 2 & 2 & 0 & 0 & 0 & 44 & 2 & 2 & 2 \\
\hline & Fall & 59 & 1 & 1 & 0 & 0 & 0 & 59 & 1 & 1 & 0 \\
\hline & Winter & 77 & 4 & 8 & 1 & 0 & 0 & 78 & 4 & 8 & 6 \\
\hline & Total & 229 & 9 & 13 & 3 & 1 & 1 & 232 & 10 & 14 & 20 \\
\hline \multirow[t]{5}{*}{2002} & Spring & 91 & 6 & 6 & 0 & 0 & 0 & 91 & 6 & 6 & na \\
\hline & Summer & 46 & 3 & 3 & 0 & 0 & 0 & 46 & 3 & 3 & na \\
\hline & Fall & 66 & 0 & 0 & 0 & 0 & 0 & 66 & 0 & 0 & na \\
\hline & Winter & 74 & 2 & 2 & 0 & 0 & 0 & 74 & 2 & 2 & na \\
\hline & Total & 277 & 11 & 11 & 0 & 0 & 0 & 277 & 11 & 11 & na \\
\hline
\end{tabular}


latitudes reduced average annual effort by about $95 \%$ for swordfish-targeted longline fishing. The order also required to board observers on swordfish-targeted fishing trips to monitor fishing activities. It also required closing all sorts of fishing in the restricted area in April and May. Following an intense period of protests and media campaigns launched by Hawaii Longline Association, a stay was placed on the execution of the order, and the judge agreed to work with the parties to seek a reasonable compromise. The negotiation resulted in an acknowledgment that Hawaii's longline fishery is not homogenous and that vessels targeting swordfish are responsible for the majority of turtle interactions. The new order maintains more or less the same area coordinates, but the southern boundary is now at the equator. Fishing to the north of $30^{\circ} \mathrm{N}$ latitude was banned except for a limited number of sets (i.e. 370 sets) for scientific observations; however, all trips must be accompanied by observers. The ruling was to remain in effect until the completion of an environmental impact statement scheduled for 1 April 2001 (Dalzell, 2000).

The ban on swordfish longline activities forced some of the vessels primarily targeting swordfish either to leave Hawaii or to switch to tuna fishing. Later, in early 2004 , the regulations governing the longline fishery targeting swordfish were relaxed by the court conditionally as per the recommendation of the Western Pacific Region Fishery Management Council (Council). The final rule establishes a number of conservation and management measures necessary for the fishery to achieve an optimum yield while avoiding the likelihood of jeopardizing the continued existence of any species listed under ESA. The rule eliminates a seasonal closure for longline fishing in an area south of the Hawaiian Islands and reopens the swordfish-targeted longline fishery based in Hawaii. This final rule implements both a regulatory amendment recommended by the Council under the Fishery Management Plan for the Pelagic Fisheries of the Western Pacific Region and court rulings containing protective measures for sea turtles (effective 1 April 2004) made in the Hawaii Longline Association v. NMFS suit that vacated a 12 June 2002 rule (Federal Register, 2004).

In order to minimize adverse impacts on sea turtles, the swordfish-targeted longline fishery has been subjected to some restrictions. The final rule establishes an annual effort limit in the amount of 2120 shallow-sets to the north of the equator which may be collectively exerted by Hawaii-based longline vessels. It requires the exclusive use of mackereltype bait and circle hooks measuring $18 / 0$ or larger with a $10^{\circ}$ offset when making shallow sets north of the equator. Fishers are also required to carry NMFS-approved turtle de-hooking devices. The rule also sets the annual limit on the number of leatherback and loggerhead turtle interactions at 16 and 17 , respectively, while engaged in shallow-setting. The shallowsetting component of Hawaii-based longline fishery will be closed for the remainder of the calendar year when either of the two limits is reached. The number of interactions will be monitored with respect to the limits using year-to-date estimates derived from data recorded by NMFS vessel observers.
The fishers are required to notify the Regional Administrator in advance of every trip whether the longline sets made during the trip will involve shallow-setting or deep-setting. It also requires that they follow the type of setting declared throughout the fishing trip (Federal Register, 2004).

The above suggests the gravity of the sea turtle interactions issue associated with the longline fishery in Hawaii. The closure of the longline fishery may lead to a transferred market effect and a degradation of marine environment. Since the longline fishery of Hawaii represents about half of the total domestic swordfish production, restricting swordfish harvest in Hawaii may result in the substitution of supply for swordfish from other geographic regions or may lead to the identification of other transshipment points. More turtle interactions may occur in the unregulated regimes due to such transferred market effects. The demise of U.S. swordfish landings from the Hawaii fishery may be balanced by increased landings from less regulated foreign fisheries that have a much higher take of turtles, which indeed appears to have been the case. A concerted international effort would certainly be necessary to reduce turtle interactions and mortalities.

\section{Model and data}

\subsection{Conceptual framework}

Count variables are often treated as though they are continuous and the linear regression model is applied, which can result in inefficient, inconsistent, and biased estimates. Fortunately, there are a variety of models that deal explicitly with the characteristics of count outcomes (Long, 1997). Count data models are relevant when the variables of interest are non-negative integer-valued random variables. They have been used in analyzing fatal accidents, patenting behavior, product innovation and discoveries, research publications, demand for health care, recreational trips, and marketing, etc. (Trivedi, 1997). These events are count variable and the Poisson model, which makes use of the integer nature of the data, is more appropriate.

The Poisson distribution is a discrete representation of count data. The Poisson process describes the frequency of an event per period of time. Also, when the Poisson model is correct, the implied mean-variance restriction makes it an efficient technique. The Poisson regression model assumes that the parameter, $\lambda$, for each case $i$ is given by

$\lambda_{i}=\exp \left(X_{i}^{\prime} \beta\right)$

where, $\lambda$ is a function of a vector of regressors, and is also the expected value of any Poisson random variable of the $i$ th entity at time $t ; X_{i}$ a vector of $i$ th entity's characteristics and other explanatory variables; $\beta$ is a conformable matrix of unknown parameters to be estimated. Rare events, such as discoveries or accidents, etc. are assumed to occur according 
to a Poisson process. The parameter $\lambda$ is known as the rate of occurrences since it is the expected number of times that an event has occurred per unit of time, and $\lambda$ can also be thought of as the mean or expected count (Long and Freese, 2001). The exponential functional form in (1) ensures a nonnegative $\lambda$ for all values of $X$ and $\beta$. This specification is attractive because it is consistent with the integer nature of rare events data and, in particular, one may often observe non-occurrences of events at any given time. Thus, the basic Poisson model captures the discrete and non-negative nature of the dependent variable and allows one to draw inference on the probability of the occurrences of an event.

The Poisson model is derived from two assumptions: (i) the probability that an event occurs within a small interval of time, $\Delta t$, is given by $\lambda \Delta t$; (ii) occurrences in disjoint time intervals are independent events (Michener and Tighe, 1992). The basic Poisson probability specification is given as (Long and Freese, 2001):

$\operatorname{Pr}(y \mid \lambda)=\frac{\mathrm{e}^{-\lambda} \lambda^{y}}{y !}, \quad$ for $y=1,2,3, \ldots, \infty$

where, $y$ is a random variable indicating the number of times an event has occurred. The following assumptions are made about the Poisson distribution (Long and Freese, 2001): (i) $\lambda$ is the mean of the distribution and as $\lambda$ increases, the mass of the distribution shifts to the right; (ii) $\lambda$ is also the variance, and thus, $\operatorname{var}(y)=\lambda$, which is known as equi-dispersion; (iii) as $\lambda$ increases, the probability of a zero count decreases, and for many count variables, there are more observed zeros than predicted by the Poisson distribution; (iv) as $\lambda$ increases, the Poisson distribution approximates a normal distribution.

The most important variable in cross-sectional studies of accidents is some measure of scale. For example, the scale variable in highway fatalities studies can be the vehicle miles traveled, and the number of registered vehicles or drivers. In the case of sea turtles interactions in the longline fishery, the scale or exposure variable may be the trip length or the number of sets used during a fishing trip. It is sensible to assume that expected accidents are proportional to the scale variable, ceteris paribus. Expected accidents will have this property if the log of the scale variable is included among the explanatory variables and its coefficients equals 1 (Michener and Tighe, 1992). Different exposure times can be incorporated into the count models. Let $t_{i}$ be the amount of time that observation $i$ is at risk. If the rate (i.e. the expected number of observations for a single unit of time) for that case is $\lambda_{i}$, then we would expect $t_{i} \lambda_{i}$ to be the expected count over a period of length $t_{i}$. Then, the count equation becomes (Long and Freese, 2001):

$\lambda_{i} t_{i}=\exp \left(X_{i} \beta\right) t_{i}=\exp \left(X_{i} \beta+\ln t_{i}\right)$

The Poisson model can be estimated by the maximum likelihood method. One property of the Poisson regression model is that the variance of the data is equal to the con- ditional mean. If this property does not hold, the situation is analogous to heteroscedasticity in ordinary least squares models. In such case, the coefficient estimates are consistent, but inefficient. The mean-variance restriction will fail to hold when the expression for $\lambda$ contains an error, for example $\lambda_{i}=\exp \left(X_{i}^{\prime} \beta+\varepsilon_{i}\right)$. Even if $\lambda$ is a deterministic function of the true $X$ 's, a measurement error in the $X$ 's would introduce an error term into the relationship between $\lambda$ and measured $X$ 's. The over-dispersion that one may find is yet another manifestation of an errors-in-variables problem (Michener and Tighe, 1992). In real data, many count variables have a variance greater than the mean, which is called overdispersion. The null hypothesis of equi-dispersion should be tested and the presence of over-dispersion may suggest that the use of the negative binomial distribution is more appropriate than the Poisson (Long, 1997). The negative binomial regression model is an extension or modification of the Poisson regression model that allows the variance of the process to differ from the mean. The mean $\lambda_{i}$, is re-specified as

$\lambda_{i}=\exp \left(X_{i} \beta\right) \exp \left(\varepsilon_{i}\right)=\lambda_{i} \exp \left(\varepsilon_{i}\right)=\lambda_{i} \delta_{i}$,

where, $\exp \left(\varepsilon_{i}\right)$ has a gamma distribution with mean 1.0 and variance $\alpha$. $\varepsilon$ is a random error that is assumed to be uncorrelated with $X$, and it can be considered either as the combined effects of unobserved variables that have been omitted from the model or as another source of pure randomness. The negative binomial probability distribution is given as

$P\left(y_{i} \mid X_{i}\right)=\frac{\Gamma\left(y_{i}+v_{i}\right)}{y_{i} ! \Gamma\left(v_{i}\right)}\left(\frac{v_{i}}{v_{i}+\lambda_{i}}\right)^{v_{i}}\left(\frac{\lambda_{i}}{v_{i}+\lambda_{i}}\right)^{y_{i}}$,

where, $v_{i}=\alpha^{-1}$. Compared with the Poisson model, the negative binomial probability distribution model has an additional estimable parameter $\alpha$, such that $\operatorname{Var}\left(y_{i}\right)=E\left(y_{\mathrm{i}}\right)\left\{1+\alpha E\left(y_{\mathrm{i}}\right)\right\}$. This is a natural form of over-dispersion and the overdispersion rate, i.e. $\operatorname{Var}\left(y_{i}\right) / E\left(y_{i}\right)=1+\alpha E\left(y_{i}\right)$. The $\alpha$ is known as the dispersion parameter since an increasing $\alpha$ increases the conditional variance of $y$. The model can be estimated by the standard maximum likelihood method. If $\alpha$ is not statistically different from zero, then the simple Poisson model is more appropriate.

A marginal effect for a unit change in factor was also carried out in the present study. The marginal with respect to the $k$ th variable $X_{k}$ depends on both $\beta_{k}$ and $E(y \mid X)$, ceteris paribus. ${ }^{3}$ It is possible to compute the discrete change in the expected count for a change in $X_{k}$ from the beginning state $X_{\mathrm{S}}$ to the ending state $X_{\mathrm{E}}$. Thus, the value of the marginal depends on the levels of all variables in the model, with all variables held at their mean levels (Long and Freese, 2001). ${ }^{4}$

\footnotetext{
${ }^{3}$ For a continuous variable, marginal change in $E(y \mid X)$ is given by $\frac{\partial E(y \mid X)}{\partial X_{K}}=E(y \mid X) \beta_{K}$.

${ }^{4}$ For a discrete change, marginal change is given as $\frac{\Delta E(y \mid X)}{\Delta E\left(X_{K}\right)}=$ $E\left(y \mid X, X_{K}=X_{\mathrm{E}}\right)-E\left(y \mid X, X_{K}=X_{\mathrm{S}}\right)$.
} 


\subsection{Empirical model}

We propose a simple production model of undesirable outputs in the pursuit of an economic activity, i.e. the bycatch of sea turtles during a fishing trip. The turtles considered are believed to be threatened or endangered species which may interact with a fishing vessel, i.e. some of these species may be entangled in fishing hooks or they may ingest baits leading to death. Because of the rarity and sparse distribution of these species, their encounter with a fishing vessel is assumed to be a rare event or accident. The event or the number of turtles caught (entangled, injured, or killed) is a random variable whose distribution depends on policy variables, individual attributes, and environmental factors. The number of turtle interactions for each fishing trip may vary from zero to several. The degree of turtle interactions with a fishing vessel depends on their abundance and the technologies used in tuna or swordfish targets, such as type of bait, depth and density of hooks, lightstick color, the amount of time a gear is soaked in water, fishing location, season, etc. Hoey (1996) also suggests that it is important to recognize the differences between gear and operating styles, especially for those factors which will influence encounter rates with turtles, such as season, region, target species, set and haul time, bait, hook, lightstick use, etc.

In the production process of undesirable outputs, we model the total number of sea turtle interactions per fishing trip, which is an integer. The total time spent on fishing is assumed to be exogenous. Since catch rate is not an integer and cannot be modeled via a count process, the number of sea turtle interactions per fishing trip will depend on trip length along with other exogenous variables. The production process of sea turtles is specified with the following general functional form:

$y_{i}=t_{i}^{\theta} \exp \left(X_{i} \beta\right)$

The distribution of sea turtle catch per trip $\left(y_{i}\right)$ naturally varies with the number of days $(t)$ per trip. When a fisher spends more time fishing, the incidence of the sea turtle interactions is assumed to be higher. In other words, there is a higher utility of catching more fish, but also an increased disutility with more time spent in fishing due to the catching of turtles. If the coefficient $\theta=1$, then the incidence of sea turtle interactions is proportional to the number of days spent per fishing trip. The sea turtle catch rate increases with the trip days when $\theta>1$ and the sea turtle interactions rate decreases with the trip days when $\theta<1$. The result would be counter-intuitive if the sign of the coefficient $\theta$ in Eqs. (6) or (7) is negative. When the sign of the coefficient $\theta$ is positive, the interaction rate increases with the time at sea. However, the interaction rate increases at a diminishing rate with the time at sea if the coefficient $\theta<1$ but positive.

The other covariates of importance in the production process of turtle bycatch are hooks per float, turtle population, soak time, season, bait type, location, lightstick color, and
Table 3

Variable definitions

\begin{tabular}{|c|c|}
\hline Variable & Definition \\
\hline$y_{i}$ & $\begin{array}{l}\text { Number of sea turtles interacted with a longline vessel } \\
\text { in a trip }\end{array}$ \\
\hline ln TIME & Log of trip length in days \\
\hline LOCN & Latitude in degree averaged for all sets of a trip \\
\hline HKPF & $\begin{array}{l}\text { Number of hooks per float is averaged for all sets in a } \\
\text { trip }\end{array}$ \\
\hline POPN & $\begin{array}{l}\text { Shark catch per unit effort (CPUE) as the proxy of turtl } \\
\text { population is averaged for all sets in a trip }\end{array}$ \\
\hline SOAK & Set soak time in hours is averaged for all sets in a trip \\
\hline SESN & $\begin{array}{l}\text { Seasonal dummies }(s) \text { : equal } 1 \text { for Fall if months } \\
\text { August-October, } 0 \text { otherwise; equal } 1 \text { for Winter if } \\
\text { months November-January, } 0 \text { otherwise; equal } 1 \text { for } \\
\text { Spring if months February-April, } 0 \text { otherwise }\end{array}$ \\
\hline LSTK & $\begin{array}{l}\text { Dummy for lightstick color: equal } 1 \text { for Green, } 0 \\
\text { otherwise }\end{array}$ \\
\hline BAIT & $\begin{array}{l}\text { Bait types dummy: equal } 1 \text { for Large Squids, } 0 \\
\text { otherwise }\end{array}$ \\
\hline HIST & $\begin{array}{l}\text { Any past record of sea turtles interaction for the vessel: } \\
\text { equal } 1 \text { for yes, } 0 \text { otherwise }\end{array}$ \\
\hline
\end{tabular}

previous history of sea turtle interaction with the vessel. The empirical model is specified in Eq. (7) and the variables included in the model are defined in Table 3:

$$
\begin{aligned}
y_{i}= & \exp \left(\beta_{0}+\beta_{1} \mathrm{LOCN}+\beta_{2} \mathrm{HKPF}+\beta_{3} \mathrm{POPN}+\beta_{4} \mathrm{SOAK}\right. \\
& +\delta_{1 s} \mathrm{SESN}+\delta_{2} \mathrm{LSTK}+\delta_{3} \mathrm{BAIT} \\
& \left.+\delta_{4} \mathrm{HIST}+\theta \ln \mathrm{TIME}\right)
\end{aligned}
$$

The above model is estimated first by employing the Poisson regression technique. If an over-dispersion is found, negative binomial procedure will be applied. For better precision, the model is estimated by trip types, i.e. swordfishor tuna-targeted trips, as the longline technologies employed for these trip types varies to some extent resulting in a different degree of interactions. The analysis here is not carried out by turtle species, as there are not enough observations to conduct separate analysis by turtle species and trip types together. Instead all turtle species as a group are considered rare, threatened, or endangered. The dependent variable, $y_{i}$, includes both dead and entangled or injured turtles in the $i$ th fishing trip of a vessel or fisher. The subscript $s$, is an index of dummy variables for particular seasons. The exogenous variables included in the model are primarily bio-physical ones to which turtles were assumed to respond. The observer's data set contains many other bio-physical variables such as hook type, hook size, number of hooks, number of sets, temperature, float length, target depth, dropper length, beaufort, vessel/shooter speed, etc. These variables were investigated for their suitability in the empirical model and were not included because of their high degree of correlation with other variables, incomplete information or irrelevance. The empirical model specified in Eq. (7) is parsimonious, albeit the choice of the variables in the final formulation as presented above is rather subjective. We believe this formulation 
is efficient as well as biologically plausible and statistically sound.

The geographic location where fishers go for longline fishing can also be a factor in turtle interactions. The summer 2000 court ruling had set a demarcation line of $28^{\circ} \mathrm{N}$ above which all the longline activities were halted based on the belief that most turtle interactions occur towards the northern area. Thus, it is also important to examine whether fishing location contributed to turtle interactions with the longline fishery, as it is believed that more turtle encounters had occurred in the northern frontier. Therefore, latitude was included in the model as a location variable (LOCN).

Similarly, it is also believed that shallow set longline targeting swordfish may result in more sea turtle interactions. Density of hooks per float (HKPF) determines the depth of hooks from the sea surface, as it also sags the longline gear deep into the sea. Fishers targeting tuna place the longline gear deeper compared to those targeting swordfish. The variable (HKPF) captures both the effects of the density of hooks and their depths on turtle interaction. However, the amount of time a set is soaked in water may also affect turtle interaction. A variable (SOAK) representing the amount of soak time in hours is, therefore, included in the model.

The magnitude of turtle interactions also depends on the size of their population and their relative abundance in the fishing area. Unfortunately, there is no data available regarding the population of sea turtles for the study period. One way to estimate this data would be to proxy sea turtle population by using the data on the abundance of its natural predator in the sea, i.e. sharks. ${ }^{5}$ In a general predator-prey relationship one could postulate that the abundance of one leads to the abundance of the others. Catch per unit of effort of sharks during the fishing trip (POPN), therefore, is used as a proxy of sea turtles population. ${ }^{6}$ It is presumed that higher turtle population would in turn lead to their higher interactions with the fishery. Shark CPUE was computed as the number of sharks caught per thousand hooks in each fishing trip.

Seasonality was also examined to see whether there were seasonal differences in the incidence of sea turtle interactions.

\footnotetext{
${ }^{5}$ Most of sea turtles are preyed on when they are small, either hatchling or juvenile size. As the turtle grows in size, sharks remain the main predator. Large sharks can consume a full-size sea turtle. Predation on hatchlings is believed to be relatively high and the species most often implicated are coastal and pelagic sharks (NMFS/USFWS, 1998a; NMFS/USFWS, 1998b). Sharks are keystone predators with diverse prey items including sea turtles. Although there may be some variation on the predation and feeding habits by shark species, they are noxious to sea turtles in general.

${ }^{6}$ We included a proxy variable representing turtle population in our model because of its theoretical importance to explain turtle interaction with the longline fishery. The seasonal abundance of sharks in general as measured in terms of their CPUE is considered a good proxy of sea turtles population assuming that the latter's abundance would lead to the abundance of their predators. In a recent research study by NMFS in Hawaii that focused on the role of sharks as predators of turtles indicated that non-removal of apex predators (like sharks) from the pelagic system by longliners might actually have a deleterious effect on turtle populations via increased predation from large individuals that were previously removed by longline fishers (Boggs, 2002).
}

Three seasonal dummies, namely Fall, Winter, and Spring seasons, were included in the model with the reference season being summer. Seasonal dummies also capture the environmental and climatic conditions as well.

It is believed that sea turtles are attracted to natural bioluminescence. They may be attracted to chemical lightsticks used by the longline fishers. Longliners use lightsticks of varied colors primarily to attract swordfish. It will be useful to identify the color to which the turtles are significantly attracted to. Since about half of the users of lightsticks were using green-colored lightsticks, a dummy variable (LSTK) was included for the use of green-colored lightsticks. Similarly, type of baits may be an important determinant in turtle interactions. Squid (large and small), sauri, and mackerel are common baits used by the longline fishers. Fishers targeting swordfish mainly use large squid. The dummy variable (BAIT) takes a value of 1 if fishers used large squid as bait. ${ }^{7}$ There are also experiments on bait colors and turtle interactions, but they are not included in the observer dataset.

It is presumed that vessels that have a history of incidence of turtle interactions may be prone to similar interactions in future. Therefore, a dummy variable (HIST) for the vessel's previous history of interactions was included in the model.

The data used in the empirical estimation were obtained from the NMFS observer records located at Honolulu Laboratory. The longline logbook data as submitted by fishers after each trip were also available, but observer data was believed to be of higher quality for the present analysis. The longline observer dataset for the period 1994-2003 was used for the analysis in the present study. ${ }^{8}$ Information such as the condition of turtles (dead, live, injured), method of their capture (hooked, entangled), and hooked location (ingested, flipper) were recorded for every encountered turtle. Also recorded were the interactions with other protected species (birds and mammals), the fish species to be targeted on the trip, fish catches, and operational characteristics of each set and haul (date and time, number of floats, hooks, lightstick, location, bait types, etc.) (Skillman and Kleiber, 1998). The observer datasets were at the set level. We have aggregated set level information into trip level as the information for most of the covariates in the model, such as season, lightstick color, bait, history of previous interactions, etc., do not differ from one set to another during a trip. Moreover, trip level observations enable us to examine the effect of time at sea. Thus, there were 924 trip level observations during 1994-2003, of which 923 were used in the analysis. There were 771

\footnotetext{
${ }^{7}$ In the swordfish-targeted trips, $65 \%$ of the fishers used large squid and $30 \%$ used small squid. In the tuna-targeted trips, fishers used varieties of baits: large squid (7\%), small squid (3\%), saury (46\%), mackerel (1\%), mixed baits $(18 \%)$ and other baits $(25 \%)$.

8 The Longline Observer Program instituted by NMFS began its operation in 24 February 1994 to collect data on the interaction between longline fishery and protected marine species. It used stratified random sampling where samples were drawn proportionately from each type of fishing trip namely swordfish trip, tuna trip, mixed trip, and switcher category (Skillman and Kleiber, 1998)
} 
Table 4

Poisson regression outcome of sea turtle interaction in bigeye tuna-targeted longline fishery in Hawaii during 1994-2003

Dependent variable: number of sea turtles per trip $(n=771)$

\begin{tabular}{|c|c|c|c|c|c|c|c|c|}
\hline & Coefficient $(\beta)$ & S.E. & $p>Z$ & $\exp (\beta)^{\mathrm{a}}$ & $\partial y / \partial x$ & $\bar{X}$ & $\sigma_{X}$ & Minimum-maximum \\
\hline ln TIME & 1.3816 & 0.4750 & 0.00 & 3.98 & 0.0441 & 2.90 & 0.30 & $1.38-4.11$ \\
\hline LOCN & -0.0507 & 0.0285 & 0.08 & 0.95 & -0.0016 & 18.16 & 5.65 & $0.00-30.73$ \\
\hline HKPF & -0.1194 & 0.0242 & 0.00 & 0.89 & -0.0038 & 26.33 & 5.67 & $4.00-38.00$ \\
\hline POPN & 0.0920 & 0.0469 & 0.05 & 1.10 & 0.0029 & 3.48 & 2.44 & $0.05-17.16$ \\
\hline SOAK & -0.0377 & 0.0719 & 0.60 & 0.96 & -0.0012 & 18.77 & 2.19 & $7.68-44.12$ \\
\hline \multicolumn{9}{|l|}{ Season $^{b}$} \\
\hline Winter & 0.4184 & 0.4312 & 0.33 & 1.52 & 0.0143 & 0.36 & 0.48 & $0-1$ \\
\hline Spring & 0.7665 & 0.4604 & 0.10 & 2.15 & 0.0306 & 0.24 & 0.43 & $0-1$ \\
\hline Fall & -0.5773 & 0.4758 & 0.23 & 0.56 & -0.0161 & 0.25 & 0.43 & $0-1$ \\
\hline HIST $^{b}$ & 0.2172 & 0.3052 & 0.48 & 1.24 & 0.0071 & 0.34 & 0.47 & $0-1$ \\
\hline $\mathrm{BAIT}^{\mathrm{b}}$ & 0.8346 & 0.4983 & 0.09 & 2.30 & 0.0401 & 0.04 & 0.20 & $0-1$ \\
\hline Constant & -3.3006 & 2.1690 & 0.13 & & & & & \\
\hline \multicolumn{5}{|c|}{ Goodness-of-fit $\chi^{2}=206.02$} & \multicolumn{4}{|c|}{$p>\chi^{2}(760)=1.00$} \\
\hline \multicolumn{9}{|c|}{ Measures of fit for Poisson } \\
\hline \multirow{3}{*}{\multicolumn{2}{|c|}{$\begin{array}{l}\text { Log-likelihood intercept only } \\
\text { D(760) }\end{array}$}} & & \multicolumn{2}{|c|}{-203.92} & \multicolumn{3}{|c|}{ Log-likelihood full model } & -151.23 \\
\hline & & & \multicolumn{2}{|c|}{302.46} & \multicolumn{3}{|l|}{ LR (10) } & 105.39 \\
\hline & & & & & \multicolumn{3}{|c|}{ Prob $>$ LR } & 0.00 \\
\hline \multicolumn{3}{|c|}{ McFadden's $R^{2}$} & \multicolumn{2}{|c|}{0.25} & \multicolumn{3}{|c|}{ McFadden's adj $R^{2}$} & 0.20 \\
\hline \multicolumn{3}{|c|}{ Maximum likelihood $R^{2}$} & \multicolumn{2}{|c|}{0.128} & \multicolumn{3}{|c|}{ Cragg and Uhler's $R^{2}$} & 0.31 \\
\hline \multicolumn{3}{|l|}{ AIC } & \multicolumn{2}{|c|}{0.42} & \multicolumn{3}{|l|}{$\mathrm{AIC}^{*} \mathrm{n}$} & 324.46 \\
\hline \multicolumn{3}{|l|}{$\mathrm{BIC}$} & \multicolumn{2}{|c|}{-4749.78} & \multicolumn{2}{|l|}{ BIC' } & & -38.91 \\
\hline
\end{tabular}

${ }^{\mathrm{a}} \exp (\beta)=$ factor change in expected count for a unit increase in $X$. Factor change implies the expected count changes by a factor of exp $\left(\beta_{k}\right)$ for a unit change in $X_{k}$, holding all other variables constant.

$\mathrm{b}$ The marginal effect $\partial y / \partial x$ is for discrete change of dummy variable from 0 to 1 .

observations associated with tuna-targeted trips, and 152 with swordfish-targeted trips. The dataset represented about $4 \%$ of the entire longline trips during 1994-1999, but $18 \%$ during 2000-2002.9

\section{Results and discussions}

The empirical specification in Eq. (7) was initially estimated by using the Poisson regression procedure. ${ }^{10}$ The selection of the Poisson model for the tuna-targeted trips was found to be appropriate as the deviance statistic was negligible implying the absence of over-dispersion in the model; however, the negative binomial regression procedure was adopted for the swordfish-targeted trips because of overdispersion. The Poisson and negative binomial regression coefficient estimates along with the goodness-of-fit statistics for the tuna- and swordfish-targeted trips, respectively, are presented in Tables 4 and 5. The following discussion for each parameter is given on the basis that all other parameters are unchanged.

A scale or exposure variable ln TIME was introduced in the model to see if sea turtle interactions rate is proportionate

\footnotetext{
9 There are very few trip level observations for year 2003; however, the ones available were also included in the analysis.

10 Stata version 8.0 econometric/statistical software was used in the model estimation and further analysis.
}

to the time spent at sea (trip days). The significance of the coefficient $(\theta)$ of this variable supports modeling turtle interactions on a per trip basis rather than on interactions rate. $\mathrm{A}$ coefficient of greater, equal to, or $<1$ implies increasing, proportionate, or decreasing amount of turtle interactions rate with the amount of time spent at sea by the fishing vessel, respectively. The result can also be interpreted analogous to elasticity measures. The coefficient less than 1 for the variable ln TIME suggests the magnitude of turtle interactions to be $<1 \%$ for each percent increase in trip days, and vice versa for a coefficient $>1$. The estimated coefficient of the scale variable in our analysis is positive and substantial but $<1$, indicating that the sea turtle interaction rate decreased with increased time spent at sea in swordfish-targeted trips. However, the turtle interactions rate increased with increasing time spent at sea in tuna-targeted trips.

Higher turtle interactions occurred toward the equator for tuna-targeted trips. However, the latitude had no effect on turtle interactions in swordfish-targeted trips. This may appear to be counter intuitive to the widely perceived view that latitude has an effect on sea turtle interactions in Hawaii's longline fishery. The effect of the latitude variable on turtle interactions in the swordfish-targeted trips might have been diluted because of the time-series data, as the most frequently caught loggerhead turtles during swordfish trips tend to be associated with the ocean frontal system. The drift of the oceanic frontal system across time, i.e. the oceanic frontal system moves on a north-south oscillation on a decadal scale, could 
Table 5

Negative binomial regression outcome of sea turtle interaction in swordfish-targeted longline fishery in Hawaii during 1994-2003

\begin{tabular}{|c|c|c|c|c|c|c|c|c|}
\hline & Coefficient $(\beta)$ & S.E. & $p>Z$ & $\exp (\beta)^{\mathrm{a}}$ & $\partial y / \partial x$ & $\bar{X}$ & $\sigma_{X}$ & Minimum-maximum \\
\hline ln TIME & 0.6035 & 0.3672 & 0.10 & 1.83 & 0.6342 & 3.15 & 0.41 & $1.94-4.06$ \\
\hline LOCN & -0.0068 & 0.0351 & 0.85 & 0.99 & -0.0071 & 28.64 & 4.71 & $18.50-38.44$ \\
\hline HKPF & -0.0731 & 0.0854 & 0.39 & 0.93 & -0.0767 & 4.81 & 3.04 & $3.00-29.66$ \\
\hline POPN & 0.0109 & 0.0054 & 0.05 & 1.01 & 0.0114 & 19.13 & 20.34 & $0.51-172.72$ \\
\hline SOAK & 0.1743 & 0.0755 & 0.02 & 1.19 & 0.1831 & 19.91 & 1.76 & $12.50-25.50$ \\
\hline \multicolumn{9}{|l|}{ Season $^{b}$} \\
\hline Winter & 0.7405 & 0.3910 & 0.06 & 2.10 & 0.9441 & 0.27 & 0.45 & $0-1$ \\
\hline Spring & 0.4721 & 0.3548 & 0.18 & 1.60 & 0.5412 & 0.34 & 0.47 & $0-1$ \\
\hline Fall & 0.4505 & 0.4378 & 0.30 & 1.57 & 0.5554 & 0.16 & 0.37 & $0-1$ \\
\hline LSTK_green $^{b}$ & 0.7433 & 0.2199 & 0.00 & 2.10 & 0.8643 & 0.39 & 0.49 & $0-1$ \\
\hline HIST $^{\mathrm{b}}$ & 0.0999 & 0.2197 & 0.65 & 1.11 & 0.1058 & 0.42 & 0.50 & $0-1$ \\
\hline $\mathrm{BAIT}^{\mathrm{b}}$ & -0.1343 & 0.2200 & 0.54 & 0.87 & -0.1441 & 0.65 & 0.48 & $0-1$ \\
\hline Constant & -5.6613 & 1.7477 & 0.00 & & & & & \\
\hline $\ln \alpha$ & -0.3793 & 0.2641 & & & & & & \\
\hline$\alpha$ & 0.6842 & 0.1807 & & & & & & \\
\hline \multicolumn{4}{|c|}{ Likelihood-ratio test of $\alpha=0: \chi^{2}(01)=48.43$} & & \multicolumn{4}{|l|}{$p>\chi^{2}=0.000$} \\
\hline \multicolumn{9}{|c|}{ Measures of fit for negative binomial regression } \\
\hline \multirow{3}{*}{$\begin{array}{l}\text { Log-likeliho } \\
\text { D(139) }\end{array}$} & tercept only & & -248.15 & & \multicolumn{2}{|c|}{ Log-likelihood full model } & & -224.18 \\
\hline & & & 448.36 & & \multicolumn{2}{|c|}{$\operatorname{LR}(11)$} & & 47.94 \\
\hline & & & & & \multicolumn{2}{|l|}{ Prob $>$ LR } & & 0.00 \\
\hline \multicolumn{2}{|c|}{ McFadden's $R^{2}$} & & 0.097 & & \multicolumn{2}{|c|}{ McFadden's Adj $R^{2}$} & & 0.044 \\
\hline \multicolumn{2}{|c|}{ Maximum likelihood $R^{2}$} & & 0.27 & & \multicolumn{2}{|c|}{ Cragg and Uhler's $R^{2}$} & & 0.28 \\
\hline \multicolumn{2}{|c|}{ AIC } & & 3.12 & & \multicolumn{2}{|c|}{$\mathrm{AIC}^{*} \mathrm{n}$} & & 474.36 \\
\hline \multicolumn{2}{|l|}{$\mathrm{BIC}$} & & -249.95 & & \multicolumn{2}{|l|}{ BIC' } & & 7.31 \\
\hline
\end{tabular}

be a plausible reason for a negligible latitudinal effect on turtle interactions. By contrast, tuna vessels tend to encounter more leatherback and olive ridley turtles, which both use the more latitudinally stable equatorial currents as migration pathways, closer to the equator.

Turtle interactions tend to be lower for a higher number of hooks per float in both tuna and swordfish trips, however, the effect is substantial in tuna-targeted trips only. In tuna trips, for every additional hook per float, incidence of sea turtle interactions decreased by a factor of 0.89 . However, the gear soak time did not have an effect on turtle interactions in tunatargeted trips, but has a substantial positive interactions in swordfish-targeted trips. For each hour increase in soak time, turtle interactions increase by a factor of 1.19 in swordfishtargeted trips.

An increase in shark CPUE, the proxy for turtle population level, had a substantial effect on turtle interactions in both the tuna- and swordfish-targeted fishing trips. For each unit increase in shark CPUE, the expected number of turtle interactions increase by a factor of 1.10 in tuna-targeted trips, and 1.01 in swordfish-targeted trips.

Seasonal differences in sea turtle interactions with the longline fishery were also investigated. The incidence of sea turtle interactions was found to be higher during winter and spring in swordfish- and tuna-targeted trips, respectively. A similar observation was found in Taiwanese coastal setnet fisheries for the period 1991-1995 where most turtle interactions of same turtle species occurred between November and March (Cheng and Chen, 1997).

Green-colored lightsticks had a substantial positive impact on turtle interactions compared to other colors in swordfishtargeted trips, with the expected number of turtle interactions increasing by a factor of 2.10 . This result reinforces the preliminary finding by Kleiber and Boggs (2000) that turtles are more attracted to green light sticks than yellow ones. The use of large squid as baits had a substantial effect on turtle interactions in tuna trips, but not in swordfish-targeted trips.

Analogous to the auto insurance industry, in which a risky driver would have to pay a higher premium for any history of auto accident or traffic violation, it was examined how a vessel which had a previous history of sea turtle interactions would pose a similar risk in future. However, HIST dummy did not reveal any substantial turtle interactions in either trip types suggesting the interactions are random events.

The marginal effects $(\partial y / \partial y)$ on the counts of turtle interactions for a change in the variables under consideration were also analyzed (Tables 4 and 5). The marginal effect of a unit increase in hooks per float decreased the incidence of turtle interactions by 0.0038 counts in tuna trips. Similarly, the incidence of sea turtle interactions in relation to a discrete 
Table 6

Number of sea turtles encounter prevented by some fishery regulation

\begin{tabular}{|c|c|c|c|c|c|c|c|}
\hline \multirow[t]{2}{*}{ Year } & \multirow[t]{2}{*}{$\begin{array}{l}\text { Longline revenue } \\
\text { (\$ million) }\end{array}$} & \multicolumn{2}{|l|}{ Number of trips } & \multicolumn{2}{|c|}{ Estimated turtle takes } & \multicolumn{2}{|c|}{$\begin{array}{l}\text { Number of turtles } \\
\text { avoided by prohibiting }\end{array}$} \\
\hline & & $\begin{array}{l}\text { Tuna-targeted } \\
\text { trips }\end{array}$ & $\begin{array}{l}\text { Swordfish-targeted } \\
\text { trips }\end{array}$ & Study 1 & Study 2 & Green lightsticks & $\begin{array}{l}\text { Swordfish } \\
\text { harvest in winter }\end{array}$ \\
\hline 1991 & 38.70 & 556 & 1115 & 694 & n.a. & 432 & 252 \\
\hline 1992 & 40.19 & 458 & 808 & 823 & n.a. & 313 & 182 \\
\hline 1993 & 45.44 & 542 & 650 & 911 & n.a. & 252 & 147 \\
\hline 1994 & 36.37 & 568 & 538 & 766 & 737 & 208 & 121 \\
\hline 1995 & 36.64 & 682 & 443 & 691 & 605 & 171 & 100 \\
\hline 1996 & 34.25 & 657 & 443 & 739 & 665 & 171 & 100 \\
\hline 1997 & 38.72 & 745 & 380 & 602 & 536 & 147 & 86 \\
\hline 1998 & 38.75 & 760 & 380 & n.a. & 666 & 147 & 86 \\
\hline 1999 & 39.69 & 795 & 369 & n.a. & 655 & 143 & 83 \\
\hline 2000 & 43.24 & 840 & 294 & n.a. & n.a. & 114 & 66 \\
\hline 2001 & 26.93 & 1031 & 46 & n.a. & n.a. & 18 & 10 \\
\hline Mean (1991-2001) & & & & 747 & 644 & 192 & 112 \\
\hline
\end{tabular}

Note: Studies 1 and 2 are by Kleiber (1998) and McCracken (2000), respectively.

change in fishing activities - the use of green-colored lightsticks against other colors-increased by 0.8643 counts, and a unit increase in sharks CPUE increased the incidence of turtle interactions by 0.0114 counts in swordfish-targeted trips. The marginal effect estimates derived from the model can also be used to predict the number of turtle casualties, which can also be interpreted as the number of turtle interactions that could have been prevented if the related policy were feasible. For example, it can be inferred that approximately 192 and 112 turtles could have been prevented from interacting with the swordfish-targeted longline trips by prohibiting the use of green lightsticks and by avoiding longline fishing in the winter season, respectively (Table 6). The estimates, however, are to be cautiously interpreted because the confidence intervals of these estimates are wide.

Table 7 presents the observed and predicted probabilities for different numbers of turtle incidences with the swordfishand tuna-targeted longline trips. The predicted number of zero sea turtle interactions is overwhelming, as the probability of zero catch is about $94 \%$ and $45 \%$ in tuna and swordfish

Table 7

Observed and predicted probabilities for each sea turtle count

\begin{tabular}{llllll}
\hline Counts & \multicolumn{2}{l}{$\begin{array}{l}\text { Tuna-targeted trips } \\
\text { Poisson probabilities }\end{array}$} & & \multicolumn{2}{l}{$\begin{array}{l}\text { Swordfish-targeted trips } \\
\text { negative binomial probabilities }\end{array}$} \\
\cline { 2 - 3 } \cline { 5 - 6 } \cline { 5 - 5 } & Observed & Predicted & & Observed & Predicted \\
\hline 0 & 0.9403 & 0.9414 & & 0.4379 & 0.4530 \\
1 & 0.0519 & 0.0499 & & 0.2549 & 0.2341 \\
2 & 0.0052 & 0.0066 & & 0.1242 & 0.1229 \\
3 & 0.0026 & 0.0016 & & 0.0654 & 0.0686 \\
4 & 0.0000 & 0.0004 & & 0.0261 & 0.0406 \\
5 & 0.0000 & 0.0001 & & 0.0261 & 0.0251 \\
6 & 0.0000 & $1.69 \mathrm{E}-05$ & & 0.0392 & 0.0161 \\
7 & 0.0000 & $2.97 \mathrm{E}-06$ & & 0.0065 & 0.0107 \\
8 & 0.0000 & $4.73 \mathrm{E}-07$ & & 0.0000 & 0.0073 \\
9 & 0.0000 & $6.89 \mathrm{E}-08$ & & 0.0065 & 0.0051 \\
10 & 0.0000 & $9.24 \mathrm{E}-09$ & & 0.0065 & 0.0036 \\
11 & 0.0000 & $1.15 \mathrm{E}-09$ & & 0.0065 & 0.0026 \\
\hline
\end{tabular}

trips, respectively. In any given trip, the predicted probabilities of sea turtle interactions with at least one turtle is about $6 \%$ and $55 \%$ in the tuna- and swordfish-targeted trips, respectively. The probabilities with counts of two or more turtles drastically decline in tuna-targeted trips, but it is higher in swordfish-targeted trips. The counts follow the Poisson distributional form. Probability declines as the count increases. There is a close match between the observed and predicted probabilities.

The above results were collected from a natural setting, however, there has been some advanced research and experimentation in Hawaii's longline fishery recently to investigate sea turtle's visual, taste, and odor receptive behaviors, interactions with various hook types, etc. (NMFS, 2001). When adequate observations become available, the results of these experiments may also provide a basis of comparison for some of the results in the present study.

\section{Concluding remarks}

The present study analyzed the production of undesirable outputs, i.e. the bycatch of sea turtles during a fishing trip, in the pursuit of an economic activity in Hawaii's longline fishery. The analysis used data for the period 1994-2003. The commercial fishing industry in Hawaii nearly halted due to environmental concerns associated with its sea turtle interactions. Because of the different interests of the stakeholders on the issue, this article has attempted to explore the factors and degree of sea turtle interactions with the longline fishery in an analytical framework of rare events by using count data models, or specifically the Poisson and negative binomial regression models. The analysis was based on the type of trip, tuna-target versus swordfish-target, as the technologies employed in targeting these species varied substantially resulting in different degrees of turtle interactions. Some policy options for management of the longline fishery have been drawn based on the model results. 
Factors including location, seasonality, turtle population, technologies such as bait type and hooks per float, collectively explain much of the variations in turtle interactions in tunatargeted longline fishery. However, only seasonality, a proxy of turtle population, and technologies including the color of lightstick and the amount of time longline gears are soaked, were important factors of turtle interactions in swordfishtargeted trips. Previous history of turtle interactions had a positive impact on turtle interactions, but its effect was statistically negligible in both the swordfish- and tuna-targeted trips. Some of the factors that had a substantial effect on turtle interactions can be regulated by appropriate policies. For example, restricting swordfish fishing during winter, regulating the use of green-colored lightsticks, or prohibiting the use of squid baits are a few suggestive and feasible measures resulting from the model that may help to alleviate sea turtle interactions to some degree. However, it is also important to examine how these policies would affect the total industry catch in comparison to total catch without such policies. For example, a ban on winter (November-January) fishing for swordfish would only reduce the total swordfish harvest by about $22 \%{ }^{11}$ As more turtle interactions appear to be during winter, limiting swordfish-targeted longline activities during this season would be an effective policy without substantially reducing total swordfish catches in the fishery.

The magnitude of turtle interactions was higher in swordfish-targeted trips compared to tuna-targeted trips. However, a total ban on swordfish fishing is one possible solution, but may not be in the best interest of Hawaii's longline fishers when there are ineffective or non-existence turtle regulations in the international arena. Moreover, transferred market effect may amplify the turtle problem.

At the time of this writing, a federal judge's ruling has lifted restrictions on Hawaii's beleaguered longline fishing fleet, but leaves the door wide open for prosecution if even a single sea turtle is documented (in the observers' record) as hooked in excess of either of the allowable 16 leatherback or 17 loggerhead turtles. Unless there is a dramatic development of a technology to avert turtle interactions with longline fishing, there is about a 55\% chance that at least one sea turtle will be encountered in a swordfish-targeted longline trip under the conventional technological configuration.

The United States continues to dedicate an increasing amount of resources to the preservation of endangered species within its borders and provide leadership in the conservation and management of these species. However, conservation and management of turtle population requires more than strongly focused domestic programs, as turtles are a shared international resource and their management requires cooperation across the Pacific Region (WPRFMC, 2002). While U.S. fishermen are committed to working cooperatively with U.S.

\footnotetext{
11 The remainder of the swordfish catches occurs during spring (34\%), summer (29\%), and fall (15\%). During 1991-1999 the annual average number of swordfish catches was about 51,200 . About $97 \%$ of the swordfish harvests are from swordfish targeted trips.
}

scientific and management groups to evaluate the extent of the problem and consider effective mitigation options, it seems inevitable that international cooperation will be required to effectively address sea turtle mortality resulting from interactions with the pelagic longline gear (Hoey, 1996). In any event, there is an urgent need of a concerted international effort to save turtles by establishing the threshold level of danger to these turtles through various mitigating measures and strategies aimed at reducing sea turtle interactions and fatalities among coastal and high-seas fisheries. In addition to scientific research on averting turtle interactions with the fishery, involving fishers in developing practical and successful mitigation measures should be encouraged. A thorough understanding of the biology, population dynamics, habitat and migratory pattern of sea turtles, along with the associated oceanographic conditions will also be useful in explaining sea turtle interactions. Exchange of ideas about turtles among fishery biologists has been occurring for quite a while, but more policy dialogue between nations will be necessary for effective management of sea turtles. Because of high surveillance cost and low enforceability in managing and regulating turtles, the best approach for now would be self-regulation by nations, fishers, and other stakeholders with the goal of an eventual cooperative solution.

\section{Acknowledgements}

This project was funded by the Cooperative Agreement NA17RJ1230 between the Joint Institute for Marine and Atmospheric Research (JIMAR) of the University of Hawaii and the National Oceanic and Atmospheric Administration (NOAA). The views expressed herein are those of the authors and do not necessarily reflect the views of NOAA or any of its subdivisions. The authors would like to thank the two anonymous reviewers and the editor of this journal, and the participants of the Pelagic Fishery Research Program's Principal Investigators' meeting held in Hawaii during December 2003 for their helpful comments and suggestions. The authors are responsible for any remaining errors.

\section{References}

Boggs, C., 2002. Population biology of Pacific ocean sharks. Progress Report for 2001, JIMAR/PFRP, Honolulu, Hawaii.

Boggs, C.H., Ito, R.Y., 1993. Hawaii's pelagic fisheries. Mar. Fish. Rev. 55 (2), 69-82.

Cameron, C.A., Trivedi, P.K., 1998. Econometric models based on count data: comparisons and applications of some estimators and tests. J. Appl. Economet. 1 (1), 29-53.

Cheng, I.J., Chen, T.H., 1997. The incidental capture of five species of sea turtles by coastal setnet fisheries in the Eastern waters of Taiwan. Biol. Conserv. 82, 235-239.

Cincera, M, 1997. Patents, R\&D, and technological spillovers at the firm level: some evidence from econometric count models for panel data. J. Appl. Economet. 12, 265-280. 
Cousins, K., 2002. Interpretation of the U.S. ESA sea turtle recovery plans. In: Kinan, Irene (Eds.), Proceedings of the Western Pacific Sea Turtle. Cooperative Research and Management Workshop. Western Pacific Regional Fishery Management Council, Honolulu, Hawaii.

Curran, D.S., Boggs, C.H., He, X., 1996. Catch and Effort from Hawaii's Longline Fishery Summarized by Quarters and Five Degree Squares, NOAA-TM-NMFS-SWFSC-225. NOAA Technical Memorandum NMFS, Honolulu, Hawaii.

Dalzell, P., 2000. Fishing, turtles and the law: recent events in the Hawaiibased longline fishery. In: Fishery Information Newsletter \#93. Western Pacific Regional Fishery Management Council, Honolulu, Hawaii (April-June 2003).

Dollar, R.A., 1992. Annual report of the 1991 Western Pacific longline fishery. Honolulu Laboratory, NMFS, Honolulu, Hawaii.

Federal Register, 2004. Rules Regul. 69 (64), 17329-17354.

Grogger, J., 1990. The Deterrent effect of capital punishment: an analysis of daily homicide count. J. Am. Stat. Assoc. 85 (410), 295-303.

Hausman, J.H., Brown, H., Griliches, Z., 1984. Econometric models for count data with an application to the patents-R\&D relationship. Econometrica 52 (4), 909-938.

Hoey, J.J., 1996. Distribution of pelagic longline fisheries in the Western Atlantic Ocean. In: Proceedings of the Industry Academic and Government Experts, and Stakeholders Workshop on Pelagic Longline Fishery-Sea Turtle Interactions, Silver Spring, Maryland, May 24-25, 1994, Compiled by Phil Williams et al., U.S. Department of Commerce, NMFS, NOAA Technical Memorandum NMFS-OPR-7, February 1996.

Hsia, T.F., 2002. Tackling of Bycatch of Sea Turtles and Seabirds by Taiwan Longline Fishery. Overseas Fisheries Development. Council of the Republic of China. Report submitted to the Second International Fishers' Forum on Solving the Incidental By-Catch of Seabirds and Turtles in the Longline Fisheries. Honolulu, Hawaii, November 19-22, 2002.

Ito, R., Machado, W.A., 2001. Annual report of the Hawaii-based longline fishery for 2000. NMFS, Honolulu, Hawaii.

Jensen, E.J., 1987. Research expenditures and the discovery of new drugs. J. Ind. Econ. 36 (1), 83-95.

Kleiber, P., 1998. Estimating annual takes and kills of sea turtles by the Hawaiian longline fishery, 1991-1997, from Observer Program and Logbook data. Honolulu Lab., NMFS, Administrative Report H-9808. Honolulu, Hawaii.

Kleiber, P., Boggs, C., 2000. Workshop on reducing sea turtle takes in longline fisheries, Miami, August 31 to September 1, 1999. Southwest Fisheries Science Center Administrative Report H-00-09, Honolulu, Hawaii.

Long, J.S., 1997. Regression Models for Categorical and Limited Dependent Variables. Sage Publications, Thousands Oaks, California.
Long, J.S., Freese, J., 2001. Regression Models for Categorical Dependent Variables Using Stata. Stata Press, Texas.

McConnell, K.E., Strand, I.E., Hedges, L.B., 1995. Random utility models of recreational fishing: catching fish using a Poisson process. Mar. Resour. Econ. 10, 247-261.

McCracken, M.L., 2000. Estimation of sea turtle take and mortality in the Hawaiian longline fisheries. Honolulu Lab., NMFS, Administrative Report H-00-06 August 2000. Honolulu, Hawaii.

Michener, R., Tighe, C., 1992. A Poisson regression model of highway fatalities. Am. Econ. Rev. 82 (2), 452-456.

NMFS/USFWS. 1998a. Recovery Plan for U.S. Pacific population of the Leatherback turtle. NMFS, Silver Spring, Maryland.

NMFS/USFWS. 1998b. Recovery Plan for U.S. Pacific population of the Loggerhead turtle. NMFS, Silver Spring, Maryland.

NMFS 2001. Program Review 2001. Honolulu Laboratory, Honolulu, Hawaii.

O'Neill, M.F., Faddy, M.J., 2003. Use of binary and truncated negative binomial modeling in the analysis of recreational catch data. Fish. Res. 60, 471-477.

Pooley, S.G., 1993. Hawaii's marine fisheries: some history, long-term trends, and recent developments. Mar. Fish. Rev. 55 (2), 7-16.

Sarker, R., Surry, Y., 1998. Economic value of big game hunting: the case of moose hunting in Ontario. J. For. Econ. 4 (1), 2960 .

Skillman, R.A., Kleiber, P., 1998. Estimation of Sea Turtle Take and Mortality in the Hawaii-based longline fishery, 1994-1996. NOAATM-NMFS-SWFSC-257, Honolulu, Hawaii.

Trivedi, P.K., 1997. Econometric models of count events. J. Appl. Economet. 12, 199-201.

WPRFMC (Western Pacific Regional Fishery Management Council), 1995. Pelagic Fishing Methods in the Pacific. Pacific Profiles. Honolulu, Hawaii.

WPRFMC (Western Pacific Regional Fishery Management Council), 2001. Pelagic Fisheries of the Western Pacific Region 1999 Annual Report. Honolulu, Hawaii.

WPRFMC (Western Pacific Regional Fishery Management Council), 2002. In: Kinan, Irene (Eds.), Proceedings of the Western Pacific Sea Turtle. Cooperative Research and Management Workshop. Honolulu, Hawaii.

WPRFMC (Western Pacific Regional Fishery Management Council), 2004a. Management measures to implement new technologies for the Western Pacific Pelagic Longline Fisheries. A regulatory Amendment to the Fishery Management Plan for the Pelagic Fisheries of the Western pacific region, March 5, 2004. Honolulu, Hawaii.

WPRFMC (Western Pacific Regional Fishery Management Council), 2004b. Pelagic Fisheries of the Western Pacific Region, 2002 Annual Report. Honolulu, Hawaii. 